\title{
Trabalho, temporalidade e representaçôes sociais de gênero: uma análise da articulação entre trabalho doméstico e assalariado
}

\section{RAFAELA CYRIN0*}

\section{Resumo}

Este artigo se propõe a investigar a categoria "trabalho e gênero", a partir da articulação entre trabalho doméstico e assalariado, considerando-se que um dos fatores centrais que explica as inserções desiguais de homens e mulheres no mercado de trabalho refere-se justamente à questão da conciliação entre trabalho e vida familiar. Apesar de ser um enfoque preliminar, pretende-se desenvolver uma hipótese de pesquisa a ser analisada em estudos complementares, acerca do caráter de centralidade que 0 trabalho assume na vida das mulheres, de uma maneira geral. Desta forma, o presente estudo visa a contribuir, de alguma forma, para o avanço de pesquisas que analisem as complexas relações entre carreira e a vida familiar.

Palavras-chave: Trabalho doméstico. Trabalho assalariado. Relações de gênero. Carreira e vida familiar. Temporalidade.

\footnotetext{
* Professora e pesquisadora da PUC de MG. Doutoranda em Sociologia pela UFM G, mestre em Psicologia das organizações pela UFSC.
} 


\section{Introdução}

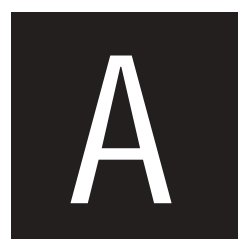

Sociologia do gênero se vem configurando, cada vez mais, como um campo de conhecimento legítimo no espaço acadêmico. Vários autores como Scott (1991) e Tilly (1994) defendem que gênero é uma categoria analítica que estrutura o sistema perceptivo dos indivíduos e remete à organização concreta de toda a vida social. Apesar da evidente proliferação de abordagens calcadasnas relações de gênero, Scott (1991) alerta para a dificuldade acadêmica de se incorporar o termo gênero nos corpos de teoria já existentes.

O estudo das relações de gênero revela, certamente, uma série de dificuldades e desafios. Donna Haraway (1995) adverte que o campo da Sociologia do gênero é marcadamente conflitivo e pouco consensual, originando uma dificuldade de síntese teórica, devido à coexistência de discursos complexos, polêmicos e contraditórios no seio mesmo de produção da teoria. Barbieri (1992) ressalta que gênero é uma perspectiva teórica em andamento, advogando a necessidade de estudos empíricos que balizem as diversas perspectivas teóricas.

$\mathrm{N}$ a discussão sobre a divisão sexual do trabalho e o binarismo natureza/cultura, N ancy Chorodow (1979) foi uma autora que colocou em destaque o papel da família na produção de mulheres subordinadase estruturadas para a maternidade. N este processo, é de grande importância a análise do processo de configuração sexual dos espaços público e privado, evidenciado por Carole Pateman (1993) em O contrato sexual. A autora, partindo dos teóricos contratualistas, evidencia que, ao explicar o surgimento da sociedade civil, os teóricos do contrato social, configuram lugares diferenciados para os homens (responsáveis pela criação da política enquanto espaço público) e para as mulheres (confinadas à esfera do doméstico, vinculada historicamente ao não civil e ao apolítico). 
Embora a modernidade e a ruptura com formas mais tradicionais de organização da vida social tenham propiciado uma certa evolução na condição das mulheres, com a emergência de novos valores, ainda persistem, na contemporaneidade, relações hierárquicas entre os gêneros em que os homens assumem, na vida social, as posições dominantes e mais valorizadas. Daí a importância de estudos que considerem a dimensão do trabalho como categoria central de análise das relações de gênero, já que esta categoria incorpora, historicamente, visíveis relações de desigualdade e de poder assimétrico entre homens e mulheres.

Este artigo busca compreender melhor esta situação de desigualdade, a partir de considerações acerca da maneira diferenciada pela qual homens e mulheres manejam o seu tempo e articulam trabalho doméstico e trabaIho assalariado. Considera-se que o trabalho feminino, em comparação com o masculino, não pode ser analisado apenas sob a ótica quantitativa e da desigualdade, bem como por considerações sobre o acesso desigual de homens e mulheres no mercado de trabalho, sobre a questão da segregação sexual, sobre os indicadores de participação econômica por sexo, entre outros. É justamente a dinâmica entre as esferas pública e privada que merece ser melhor compreendida do ponto de vista das relações de gênero.

A abordagem aqui proposta parte do pressuposto de que o trabalho só pode ser bem analisado se for rompida a oposição entre âmbito doméstico e produção de mercadorias, conforme aponta Aguiar (1997). Q uando se analisa, pois, a questão dos diferentes modos de regulação nos usos do tempo sob a ótica do gênero, consideram-se as jornadas de ocupação (feminina e masculina) em sua totalidade, incluindo aí o tempo e os esforços despendidos tanto no domicílio quanto fora dele. Isso significa que a alocação diferencial homem/mulher dentro de casa e no mercado de trabalho serão considerados, nesta pesquisa, de maneira integrada. Tanto as obrigações domésticas quanto o trabalho assalariado compõem-se de atos que ocupam tempo, sendo, por conseguinte, elementos fundamentais na análise da 
organização da vida cotidiana. Portanto, para uma melhor compreensão do trabalho feminino é importante remeter-se também ao âmbito doméstico e às relações de poder que aí se encontram.

É importante ressaltar que, quando se analisa a questão da autoregulação temporal na vida cotidiana, tendo-se como eixo de análise uma abordagem calcada no gênero, deve-se adotar uma perspectiva relacional, considerando-se as diferentes inserções sociais, tanto do homem quanto da mulher no espaço doméstico e no mercado de trabalho. Este enfoque relacional permeia toda a abordagem proposta por este trabalho, pois compreende-se que gênero é um conceito que diz respeito à relação entre homens e mulheres e envolve, portanto, a relação do indivíduo com outros indivíduos e com a cultura da qual ele faz parte.

N este sentido, será viável recorrer ao conceito de representação social que, tributado originalmente aos trabalhos de Durkheim, relaciona-se, de maneira direta, a um sistema de valores, idéias e práticas que servem para orientar os membros de uma sociedade. Esta idéia parte do pressuposto de que existem determinados modos de conhecer, de compreender, de interpretar e de significar a realidade, os quais são construídos socialmente. Considerar, então, a existência de representações sociais de gênero, significa também enfatizar gênero como uma construção social.

A incorporação do conceito de representação social à análise da discussão sobre a articulação entre trabalho doméstico e trabalho assalariado permite a emergência de vários questionamentos: as mulheres se sentem, de al guma forma, responsáveis pelo espaço doméstico? Q uais são as crenças e valores mais evidentes acerca da suposta "natureza" feminina e masculina? De que maneira estas crenças e valores ajudam a entender melhor as desigualdades de gênero? Q uais são as expectativas e os papéis que assumem tanto o homem como a mulher em funções como o cuidado com os filhose a administração da casa?

Tendo-se como referência, porém, a organização da vida cotidiana e a maneira como ocorre a articulação entre trabalho doméstico e assalariado 
na dinâmica do grupo familiar, esta pesquisa procurou compreender como as pessoas se percebem enquanto homens e mulheres e quais suas opiniões acerca do papel dos homens e das mulheres no lar e na sociedade. Em termos específicos, objetivou-se:

(a) compreender, de maneira geral, como as pessoas distribuem o seu tempo, com as atividades de trabalho remunerado, com as atividades de trabalho doméstico não remunerado, com o cuidado com os fiIhos, com os estudos, com o lazer e o tempo livre das obrigações;

(b) identificar e compreender de que forma emerge a dimensão do conflito e da negociação de gênero, no que se refere à divisão das atividades domésticas;

(c) identificar, no discurso dos participantes, aspectos da representação social de gênero, no sentido de melhor compreender os aspectos mais ou menos subversivos/ tradicionais de suas práticas.

\section{M etodologia da pesquisa}

Com esta proposta de trabalho, foram desenvolvidos os grupos focais analisados no presente documento. $\mathrm{Na}$ condução dos trabalhos e em sua análise, atentou-se para a seguinte questão: o grupo focal constitui-se em análise microssocial e não permite generalizações, o que conduz a uma relativização do conhecimento obtido. A técnica dos grupos focais foi utilizada tendo em vista os seus recursos para o enfoque de opiniões e, ainda, por sua condição de destacar os interesses e valores de grupos sociais atingidos coletivamente.

O objetivo principal foi o de tratar da percepção do tempo cotidiano e do lazer sob a perspectiva de gênero. Para fins de comparabilidade e em vista do tema proposto não ser passível de causar constrangimentos nos entrevistados, optou-se por abordá-lo de forma direta nas discussões. 0 
roteiro de questões foi organizado em dois blocos: o primeiro procurou tratar da representação de gênero e divisão do trabalho. No segundo bloco foram tratadas as questões sobre lazer e usos do tempo.

De acordo com a literatura sobre grupos focais, recomenda-se, para cada projeto específico, a realização de trêsa cinco grupos (M O RGAN, 1997). No caso do presente estudo, foram realizados três grupos de discussão, sendo que um grupo foi composto somente por homens (6 participantes), outro somente por mulheres (8 participantes) e um terceiro foi um grupo misto, composto por homens e mulheres ( 6 participantes, sendo 3 homens e 3 mulheres). Somando os três grupos focais realizados, tem-se um total de 20 participantes: 11 mulherese 9 homens. Conforme o roteiro proposto para 0 grupo focal, a introdução de um grupo misto objetivou verificar se as opiniões dos participantes sofriam influências quando estes eram confrontados. Os gruposforam, ainda, integrados por indivíduos de diferentes ocupações, com trabalhadores remunerados (manuais e não-manuais), e também por aposentados, donas-de-casa, estudantes e desempregados. Todo o conteúdo dos três grupos foi gravado em fitas K7, que foram posteriormente transcritas. É importante ressaltar que, na análise de todas as informações, procurou-se considerar sempre as posições do grupo e não dos indivíduos.

Há que se destacar ainda, que a opção nesta pesquisa por uma base de recrutamento circunscrita a homens e mulheres casados e com filhos, deveu-se ao fato de ser este o perfil dos indivíduos envolvidos em muitas atividades consumidoras de tempo, conforme definição proposta por Torsten $\mathrm{H}$ agerstrand (1978), principalmente aquelas relacionadas ao "ciclo de cuidados", aplicado com bastante propriedade aos pais de filhos pequenos.

Os dados sóciodemográficos foram coletados a partir do preenchimento de um questionário, pelos participantes da pesquisa, conforme pode ser observado nas tabelas abaixo. 
Tabela 1 - Dados sóciodemográficos do Grupo M isto

\begin{tabular}{|c|c|c|c|c|c|}
\hline No & Sexo & Idade & Escolaridade & Renda familiar & O cupação \\
\hline 1 & Masculino & 44 & $1^{0}$ grau completo & 2 a $4 \mathrm{sm}$ & Vigilante \\
\hline 2 & Feminino & 46 & Superior completo & 10 a 15 sm & Dona de casa \\
\hline 3 & Feminino & 32 & $2^{\circ}$ grau completo & 1 a $2 \mathrm{sm}$ & Cabeleireira \\
\hline 4 & Feminino & 48 & $2^{\circ}$ grau completo & Mais de $15 \mathrm{sm}$ & Dona de casa \\
\hline 5 & Masculino & 33 & $2^{\circ}$ grau completo & 1 a $2 \mathrm{sm}$ & D esempregado \\
\hline 6 & Masculino & 25 & $2^{\circ}$ grau completo & 1 a $2 \mathrm{sm}$ & Rep. comercial \\
\hline
\end{tabular}

Tabela 2 - Dados sóciodemográficos do Grupo de Homens

\begin{tabular}{llclll}
\hline No & Sexo & Idade & Escolaridade & Renda familiar & $\begin{array}{l}\text { Ocupação } \\
\text { Principal }\end{array}$ \\
\hline 1 & Masculino & 31 & Superior completo & Mais de $15 \mathrm{sm}$ & Professor \\
2 & M asculino & 41 & Superior completo & Mais de $15 \mathrm{sm}$ & Adm. de empresa \\
3 & Masculino & 45 & Primário incompleto & De 2 a $4 \mathrm{sm}$ & Pedreiro \\
4 & Masculino & 43 & Superior incompleto & De 7 a $10 \mathrm{sm}$ & Microempresário \\
5 & Masculino & 40 & Superior incompleto & De 10 a $15 \mathrm{sm}$ & Funcionário público \\
6 & Masculino & 53 & 20 grau completo & Mais de $15 \mathrm{sm}$ & Comerciante \\
& & & & & \\
\hline
\end{tabular}

Tabela 3 - Dados sóciodemográficos do Grupo de Mulheres

\begin{tabular}{|c|c|c|c|c|c|}
\hline № & Sexo & Idade & Escolaridade & Renda familiar & $\begin{array}{l}\text { Ocupação } \\
\text { Principal }\end{array}$ \\
\hline $\begin{array}{l}7 \\
8 \\
9 \\
10 \\
11 \\
12\end{array}$ & $\begin{array}{l}\text { Feminino } \\
\text { Feminino } \\
\text { Feminino } \\
\text { Feminino } \\
\text { Feminino } \\
\text { Feminino }\end{array}$ & $\begin{array}{l}36 \\
36 \\
34 \\
46 \\
27 \\
50\end{array}$ & $\begin{array}{l}\text { Superior incompleto } \\
20 \text { grau completo } \\
\text { 2 grau completo } \\
\text { Superior completo } \\
\text { Superior completo } \\
\text { Superior completo }\end{array}$ & $\begin{array}{l}4 \text { a } 7 \mathrm{sm} \\
\text { Mais de } 15 \mathrm{sm} \\
\text { Mais de } 15 \mathrm{sm} \\
4 \text { a } 7 \mathrm{sm} \\
7 \text { a } 10 \mathrm{sm} \\
\text { Mais de } 15 \mathrm{sm}\end{array}$ & $\begin{array}{l}\text { Dona de casa } \\
\text { Dona de casa } \\
\text { Cabeleireira } \\
\text { Dona de casa } \\
\text { Professora } \\
\text { Técnica de } \\
\text { laboratório }\end{array}$ \\
\hline 13 & Feminino & 49 & $2^{\circ}$ grau completo & 10 a $15 \mathrm{sm}$ & $\begin{array}{l}\text { Técnica de } \\
\text { laboratório }\end{array}$ \\
\hline 14 & Feminino & 42 & Superior completo & Mais de $15 \mathrm{sm}$ & Jornalista \\
\hline
\end{tabular}


0 interesse de pesquisa residiu em observar as diferentes percepções que homens e mulheres têm dos usos do tempo em seu cotidiano e a forma pela qual as pessoas organizam as suas vidas na perspectiva dos usos do tempo. Neste sentido, a constituição dos três grupos de discussão permitiu evidenciar as diferentes percepções que homens e mulheres possuem acerca da temporalidade, do trabalho e das relações de gênero. A partir da concepção de gênero como uma categoria relacional, e conforme a orientação proposta por Barbieri (1992), este estudo procurou incluir em suas análises, a perspectiva masculina, considerando-se as diferentes formas de percepção que homens e mulheres têm da realidade e do cotidiano.

\section{Trabalho, temporalidade e relações de gênero}

Discutir a articulação entre trabalho doméstico e trabalho assalariado não é uma tarefa fácil. Existe hoje um grande debate acerca desta questão, mas as abordagens são múltiplas e, de maneira geral, pouco consensuais. U ma primeira dificuldade que se impõe refere-se à própria tentativa de definição dos termos "trabalho doméstico" e "trabalho assalariado".

Teóricos clássicos da Sociologia do Trabalho (FRIEDMANN*; NAVILLE,1973) compreendiam que as obrigações familiares e as tarefas domésticas, por se caracterizarem pela ausência de remuneração, não poderiam ser designadas como trabalho. Esta definição, entretanto, tem sido frequentemente colocada em questão por grande parte dos estudiosos das relações de gênero.

Hirata (2002), ao tomar como ponto de partida a noção de divisão sexual do trabalho enfatiza o caráter multidimensional do trabalho, entendendo por trabalho, não apenas o profissional, mas também o doméstico, 0 não-mercantil, o não remunerado, o informal. Bila Sorj (2004), ao enfatizar a articulação entre a esfera da produção econômica (trabalho remunerado) e a esfera da reprodução (família) incorporou à discussão o conceito de 
trabalho social, definido como o trabalho, tanto remunerado, quanto nãoremunerado, os quais não podem ser compreendidos de maneira isolada.

$\mathrm{N}$ a discussão acerca da articulação entre trabalho doméstico e trabaIho assalariado houve uma influência considerável de teóricos econômicos que passaram a analisar a questão da temporalidade e a maneira desigual pela qual homens e mulheres percebem e "alocam" o seu tempo na realização das mais diversas atividades cotidianas. U ma das questões mais evidenciadas no debate econômico acerca das relações de gênero diz respeito justamente à tentativa de redefinição de termos como "trabalho doméstico" e "trabalho assalariado", definidos, muitas vezes, em termos econômicos, como trabalho improdutivo e produtivo. Para M elo (2005), o grande desafio consiste em incorporar a produção doméstica não mercantil aos postulados da teoria econômica, abandonando a perspectiva de circunscrevêlo à sua dimensão, associada à geração direta de valor.

Dedecca (2004), afirmando que o debate sobre o uso do tempo no capitalismo do século XX não mais permite identificar o tempo não criador de valores de troca como tempo doméstico, analisou a PNAD (Pesquisa N acional por Amostras de Domicílio) de 2001 e observou que a jornada total de trabalho das mulheres, incluindo o trabalho doméstico e o assalariado, é nitidamente superior à dos homens. 0 autor revela ainda, que as mulheres "alocam" três vezes mais tempo do que os homens em atividades ditas "domésticas", mesmo quando o homem se encontra em situação de desemprego. É importante ressaltar, entretanto, que mesmo no que se refere à dupla jornada de trabalho, não há como homogeneizar a experiência das mulheres. Dedecca (2004), em seus estudos, ressalta que a dupla jornada de trabalho tende, muitas vezes, a estar associada à baixa remuneração, pois uma boa condição financeira pode permitir à mulher inserida no mercado de trabalho contratar profissionais que realizam boa parte do trabalho doméstico.

U m outro aspecto que passou a ser evidenciado nas pesquisas referese ao caráter de invisibilidade social das atividades ditas domésticas (M ELO, 
2005; HILDETE, 2005). De acordo com M elo (2005), as funções tradicionais que as mulheres exercem secularmente e que permanecem como encargo específico feminino, têm um caráter de invisibilidade social, sendo desqualificadas e desvalorizadas socialmente. Revelar, portanto, o trabalho doméstico, evidenciando que este se compõe não apenas de uma multiplicidade de tarefas como limpeza, arrumação, vestuário, mas inclui a socialização das criançase a manutenção dos laços familiares, é parte desse processo de desvelamento de uma realidade pouco visível à sociedade, de uma maneira geral.

\section{A conciliação entre trabalho doméstico e assalariado}

Pesquisas sobre a conciliação entre trabalho doméstico e assalariado têm sido cada vez mais frequentes na Academia. O s enfoques são variados, e os resultadosnão apontam em uma única direção. A partir de uma abordagem histórica, as pesquisas revelam que, de maneira geral, a situação da mulher melhorou, com a conquista de novos espaços de participação e direitos mais efetivos de cidadania. Entretanto, outras pesquisas enfatizam as dificuldades encontradas, os pontos de resistência e os aspectos mais negativos deste processo em busca de uma maior igualdade de gênero.

Em pesquisa realizada pela Fundação Perseu Abramo em 2001, evidenciou-se que um dos componentes mais negativos percebidos pelas mulheres no que se refere à sua situação atual refere-se à questão do excesso de responsabilidades, atribuídas principalmente à dupla jornada de trabalho. Por outro lado, a mesma pesquisa revelou que as mulheres, caso pudessem optar, escolheriam "trabalhar fora e dedicar-se menos à casa e à família", o que significa um certo desejo de rompimento com o papel de gênero tradicional. Entretanto, entre o desejo e a prática há um grande caminho a ser percorrido. A pesquisa evidencia também que, em $96 \%$ dos domicílios familiares, uma mulher é a principal responsável pela execução ou orientação dos afazeres domésticos e que a participação dos homens no 
trabalho doméstico é seletiva e diminui à medida que as atividades implicam trabalho manual.

Entre avanços e retrocessos, é inegável a constatação de que houve uma mudança social efetiva na segunda metade do século XX no que se refere à ocupação do espaço público pelas mulheres, à esfera privada e ao casamento (RAGO, 2004). Contudo, alguns pontos de resistência podem e devem ser revelados pelas pesquisas, no sentido de se compreender meIhor quais são os maiores desafios a serem enfrentados em direção a uma maior igualdade de gênero.

Bruschini (2000), ao analisar a evolução do trabalho feminino na sociedade brasileira, considera que a persistência da responsabilidade das mulheres pelos cuidados com a casa e a família é um dos fatores determinantes da posição secundária ocupada por elas no mercado de trabalho. O u seja, a constante necessidade de articular papéisfamiliarese profissionais, associada à persistência de modelos de família do tipo patriarcal pode aparecer como elemento extremamente condicionante à disponibilidade das mulherespara o trabalho.

$\mathrm{N}$ a discussão sobre as possibilidades de escolha em relação à vida em geral, torna-se fundamental resgatar o conceito de "cuidado", definido por Clara Araujo ; Ceci Scalon (2005), como a provisão diária de atenção social, física, psíquica e emocional às pessoas. As autoras revelam de que maneira o cuidado é tradicionalmente associado às mulheres e permaneceu durante muito tempo pouco visível nos estudos de gênero. A noção de cuidado, socialmente construída e "naturalizada" como atributo feminino, onera as mulheres, afetando particularmente suas vidas. As pesquisas revelam que a divisão de trabalho entre os membros de um casal no que diz respeito ao cuidado com os filhos sugere poucas mudanças nos padrões tradicionais. $A$ incorporação, portanto, deste conceito é fundamental para se resgatarem aspectos importantes das relações sociais cotidianas, para além de atividades mecânicas, tarefas, afazeres domésticos.

Mesmo que se considere, em alguns aspectos, uma enorme distância entre o critério igualitarista que fundamenta a aspiração das mulheres e a 
pronunciada desigualdade que ainda caracteriza as práticas sociais no contexto doméstico (SO RJ, 2004), é importante que se evidencie a dimensão do conflito e da negociação nas relações de gênero, pois, ao lado de situações de dominação, observam-se situações de resistência e de subversão. Barbieri (1992), ao considerar a perspectiva de gênero como conflito, evidencia justamente a presença de relações de gênero instáveis e inseguras, configurandoas como espaços contraditórios de poder e de tensão permanente.

Representações sociais de gênero:

\section{um conceito útil para a análise das relações de gênero}

0 processo de construção de um mundo mais igualitário, do ponto de vista das relações de gênero, não é linear, mas sujeito a avanços, desvios e contradições. Revelar, pois, os impasses e os desafios a serem enfrentados indica a necessidade de se rever alguns pressupostos tradicionais que impedem uma correspondência maisestreita entre o discurso e a prática do igualitarismo.

Schutz (1979), ao elaborar o conceito de "mundo da vida" indica que o homem que age sobre o mundo da vida cotidiana vivencia-o como realidade na "atitude natural", deixando de procurar a verdade e não questionando a certeza de muitos conhecimentos que são tidos como pressupostos inquestionáveis. Desta forma, costumes socialmente aceitos são transmitidos às crianças que nascem e crescem dentro do grupo e que passam a "pensar como sempre". De fato, assumir o mundo como pressuposto inquestionável implica a hipótese de que, até segunda ordem, o mundo vai continuar sendo essencialmente da mesma maneira como foi até aqui.

Esta discussão de "pressupostos inquestionáveis" é muito pertinente para a análise das relações de gênero. Donna Haraway (1995) insiste na necessidade de se quebrar a subjetividade dominadora, desqualificando as categorias analíticas como sexo ou natureza, para produzir um campo de 
diferenças de gênero aberto à significação. Sua discussão em termos de natureza e cultura indica de que maneira a Biologia foi usada para naturalizar as diferenças sexuais.

Em termos empíricos, Goldenberg (1991), em uma pesquisa realizada em 1990 sobre a construção social da identidade masculina, concluiu que a responsabilidade da administração ou da realização de grande parte doscuidados da casa e dosfilhosé ainda atribuído à mulher porque parece prevalecer na sociedade brasileira uma certa "naturalização do papel feminino", através da qual atribuem-se como parte da "natureza feminina" funções como o cuidado com os filhos, a administração da casa, entre outras. N o mesmo sentido, Clara Araujo ; Ceci Scalon (2005) afirmam que, apesar de variações importantes, há um padrão praticamente universal ao longo da História: o trabalho definido como "reprodutivo" ou doméstico é visto como feminino, e o trabalho definido domo "produtivo" ou remunerado é visto como masculino.

0 conceito de representação social é útil neste sentido porque envolve justamente o estudo de como as pessoas tratam, distribuem e representam o conhecimento, constituindo uma realidade comum e transformando idéias em práticas e costumes. As representações sociais, de acordo com Serge M oscovici (2003) são uma forma de criação coletiva e constituem um sistema de valores, idéias e práticas que são reforçadas pela tradição, constituindo-se em uma realidade social 'sui generis'. Para lidar empiricamente com este sistema de valores, uma estratégia de pesquisa frequentemente utilizada pelo autor consiste em procurar estabelecer uma distância crítica do mundo cotidiano e do senso comum em que as representações sociais circulam. Sendo gênero uma construção social, é fundamental o questionamento de representações tradicionais de gênero que contribuem para que homense mulheresse percebam de maneira a-histórica, eternizados em determinados comportamentose atitudes que são interp retad os como parte da natureza masculina ou feminina.

Finalmente, levando-se em conta a variabilidade da vida social, é importante, como propõe D onna Haraway, historicizar as categorias de sexo e 
gênero, a favor de um saber localizado que considere as subjetividades sociais emergentes, diferenciadas e contraditórias. Nesse sentido, em vez de se pretender homogeneizar a experiência de homens e mulheres, é importante considerar-se o contexto étnico e cultural nas análises de gênero, partindo-se do pressuposto de que não existe a mulher e o homem, mas mulheres e homens em diferentes situações sociais e culturais (BARBIERI,1992).

\section{Resultados da pesquisa e discussão}

A análise dos dados partiu, à luz das considerações teóricas anteriores, da comparação entre os três grupos de discussão, mediante a observação de pontos de similaridade e de confronto entre os mesmos. Para cada questão teórica considerada correspondeu um esforço de análise dos elementos presentes nas discussões que permitiriam uma melhor compreensão da mesma.

Em primeiro lugar, é importante ressaltar que a discussão nos grupos focais permitiu revelar algumas diferenças importantes de percepção entre homens e mulheres, a partir de uma perspectiva relacional que privilegiou o caráter de negociação presente nas relações de gênero. 0 critério básico de seleção dos participantes foi o estado civil: homens e mulheres casados. O utros critérios de seleção como ocupação e classe social não foram considerados neste estudo, tornando os grupos bastante heterogêneos em sua composição. Desta forma, representações heterogêneas de gênero puderam ser observadas através do relato de experiências complexas e contraditórias de homens e mulheres com experiências de vida bastante diversas. Se a heterogeneidade na composição dos grupos focais, por um lado, dificulta a generalização do conhecimento produzido, por outro lado, revela as diferentes maneiras de "ser homem" e de "ser mulher" na nossa sociedade. Barbieri (1992), a partir de seus estudos, já havia afirmado que não 
existe "a mulher" nem tampouco "o homem", mas homens e mulheres em diferentes situações sociais e culturais, que precisam ser explicitadas.

No que se refere à análise dos dados, esta permitiu evidenciar, em todos os grupos de discussão, a presença de discursos socialmente aceitáveis, os quais entravam facilmente em contradição com outros relatos e opiniões expressos pelos próprios participantes. Além disso, tais contradições revelam que o discurso nem sempre corresponde à prática. Entre um discurso de igualitarismo e uma prática livre de hábitos, costumes e valores tradicionais há uma grande distância.

A primeira pergunta proposta pela pesquisa ("se os participantes acham que os filhos devem ser educados de forma diferenciada ou não, independente do sexo") foi a que mais originou respostas socialmente aceitáveis e praticamente consensuais em todos os grupos. No grupo das mulheres, por exemplo, o discurso de que a educação (enquanto princípio) deve ser a mesma para meninas e meninos - unânime no grupo, choca-se com uma prática em que as mulheres participantes admitem serem responsáveis pelas atividadesdomésticas, afirmando sentirem-se na obrigação de assumi-las pelos mais variados motivos, conforme pode ser observado pelo discurso de uma participante: "Deveria ser assim tudo dividido, mas acaba que sobrecarrega mais para a mãe. É você que dirige sua casa e se você falar que não vai fazer, a coisa não anda. Ninguém faz, então você se sente na obrigação de fazer".

Em outras intervenções femininas, a desigualdade na divisão das tarefas domésticas também pode ser evidenciada com clareza. U ma participante chega a afirmar: "Eu acho que é meio assim mesmo, a mulher sempre acaba assumindo mais as tarefas de casa e até na criação dos filhos. Pelo menos lá em casa, assim, é, eu sinto como minha menina pede tudo para mim". A confirmação categórica de tal situação por outra participante só vem para reafirmar 
a relevância deste papel materno assumido pelas mesmas no seio do grupo familiar: "Isso é verdade! Tudo é mãe, tudo é mãe, isso é mesmo".

A ênfase na maternidade e a crença em uma certa inevitabilidade da situação de desigualdade na distribuição de tarefas domésticas tornam-se visíveis. Parece existir um senso comum de que essa situação é assim mesmo, de que é inevitável esta participação desigual de homense mulheres na vida doméstica. Conforme já apontou Bila Sorj (2004), a associação do feminino com o doméstico constitui um 'habitus' muito resistente à mudança.

Em vários trechos da discussão, percebe-se, entretanto, que, mesmo que a mulher assuma de forma nitidamente desigual as tarefas domésticas com os homens, este processo está longe de ser harmonioso, pois é sujeito a conflitos de toda ordem. O u seja, existem deferentes formas de manejo, as quais demonstram que a contestação de uma ordem tradicional é possível e que, corroborando Giddens, o processo de rotinização é produzido cotidianamente.

A seguinte fala de uma das participantes do grupo das mulheres exemplifica bem esse processo: "N esse ponto de obrigação, por exemplo, lá em casa eu brigo, não é dividido igual quando tem que fazer. Eu não assumo sozinha, não. M as não consigo dividir igual também."

Essa multiplicidade de responsabilidades assumida pelas mulheres no mercado de trabalho e em casa, é reconhecida em todos os grupos de discussão. No caso do grupo das mulheres, os afazeres domésticos são reconhecidamente assumidos como atividades altamente consumidoras de tempo. Talvez isso explique a visão, presente neste mesmo grupo, de que as mulheres devem trabalhar fora, porém em um período menor do que 0 dos homens. Q uase todas concordam que a mulher deve trabalhar menos, com a justificativa de conciliar melhor com a família. O grupo termina esta discussão sobre se a mulher deve ou não trabalhar fora de casa, concluindo que se pode até aumentar a carga horária do homem concomitantemente, 
pois, segundo o discurso de uma das participantes: "O homem deve trabaIhar o dia inteiro porque é maisfolgado".

Este posicionamento assumido pelo grupo de mulheres revela mais uma vez, aspectos contraditórios, pois o discurso de igualitarismo se choca, de uma certa maneira, com uma proposta de uma carga horária de trabalho diferenciada entre os sexos. De fato, em busca de uma maior igualdade de gênero, talvez seja mais fácil aumentar a carga horária de trabalho remunerada do homem do que aumentar a sua participação doméstica. Entretanto, se a mulher tem revelado, de uma maneira geral, nas pesquisas (VENTU RIN I ; RECAM AN, 2004), um desejo de se dedicar mais à vida profissional, em detrimento da casa e da família, a primeira opção não é a melhor, em termos de uma maior igualdade de gênero.

Comparando-se com o grupo dos homens constata-se uma grande diferença, na regulação do uso do tempo, levando-se em conta a variável sexo. Enquanto as mulheres assumem as atividades domésticas e consideram que deveriam trabalhar menos para continuar a assumi-las, os homens revelaram, na pesquisa, um posicionamento bastante diverso. Ao serem perguntados sobre a obrigação de exercerem atividades domésticas, os homens, quase em sua totalidade, afirmaram que fazem de tudo em casa, dividem com as mulheres todas as tarefas domésticas. Por outro lado, os homens deixam entrever, nas suas argumentações, que não percebem as tarefas domésticas como trabalho. 0 u seja, vários participantes identificaram as atividades que desempenham em casa como lazer: "Tenho um pouco de lazer com as minhas meninas: até elas dormirem, eu brinco com elas um pouquinho".

U ma consideração de um dos participantes do grupo misto é bastante significativa para a discussão proposta por este artigo:

$Q$ uando eu estou fazendo um trabalho diferente do trabalho do meu dia-a dia, eu considero como um lazer também. Se tiver fazendo um trabalho em casa, limpando uma horta, para mim é lazer. Não é aquela coisa do dia-a-dia, eu não ganho a vida com aquilo. À medida que eu saio do meu ambiente de trabalho, qualquer 
coisa que eu faço eu considero como lazer.

Verifica-se, então, que existe uma percepção bastante diferente dos homens e das mulheres sobre o que significa a divisão das tarefas domésticas. Enquanto as mulheres se sentem sobrecarregadas ao perceberem que assumem múltiplas tarefas, os homens consideram que estão dividindo tudo com as mulheres, inclusive o trabalho doméstico.

Pode-se tentar compreender essa diferença de percepção supondo-se a presença de um discurso masculino de divisão igualitária das tarefas domésticas dentro do socialmente aceitável. M as é possível, concomitantemente que os homens, ao considerarem o trabalho assalariado como atividade central e estruturante em suas vidas, considerem mais do que justo e normal que as atividades domésticas possuam apenas um caráter acessório e residual no seu cotidiano. 0 tempo que dispendem com tarefas domésticas, então, não é central e nem estruturante, podendo até ser considerado como lazer, pois de acordo com o depoimento de um participante: "Durante a semana, normalmente coisas que eu faço e que eu considero interessante como atividade de lazer... cuidar da minha filha, nessesmomentos de trocar fraldas, dar banho, isso para mim é extremamente prazeroso".

No caso das mulheres, a relação com as tarefas domésticas é uma relação caracterizada como de trabalho e não de lazer. U m depoimento de uma mulher do grupo misto torna clara a aceleração de ritmose cadências femininos:

Vou ser sincera demais. Eu estou, com licença da palavra, de saco cheio, saturada, não aguento mais... tô por aqui... eu não aguento mais serviço de casa...Porque eu falo "não é fácil trabalhar fora e conciliar com o serviço de casa. Você não tem opção de chegar às 9 ou 10 horasem casa, ir pro tanque, lavar roupa, estender roupa até meia noite, ter que adiantar a comida, ter que fazer isso... ter que fazer aquilo.

Embora o depoimento anterior evidencie um alto grau de rotinização e de disciplinamento na condução das tarefas domésticas, é importante ressaltar que os grupos de discussão permitiram observar que a relação da mulher com o trabalho doméstico reveste-se das mais diversas formas, desde uma completa identificação com as tarefas domésticas até uma relação 
de compromisso entre os familiares no qual a mulher faz "a sua parte", mas não assume as tarefas como exclusivamente suas.

Essa variedade de relações domésticas que pode ser construída no âmbito de cada grupo familiar foi observada pela "fala" de uma das participantes do grupo feminino:

“Eu acho que a atividade doméstica é o seu dia-a-dia... É dividir aquilo entre os familiares. Não só entre a mulher e o homem... o homem, a mulher, os filhos, a visita que vai na sua casa e toma uma água, não custa passar uma água no copo, se tem uma certa intimidade."

Houve uma certa dificuldade de compreensão dos participantes, de uma maneira geral, ante a questão proposta acerca de a quais atividades os homens e as mulheres devem dedicar-se mais tempo. No caso do grupo doshomens, a pergunta teve de ser repetida diversas vezese, no grupo das mulheres, houve uma "falação conjunta" que tornou impossível transcrever o trecho inicial da discussão. Isso pode indicar que tal questionamento gerou algum tipo de conflito por envolver questões polêmicas, ou um assunto difícil de ser abordado discursivamente.

O grupo dos homens, após uma dificuldade inicial de compreensão da pergunta, foi bastante enfático ao relacionar o trabalho como a principal atividade a que o homem deve dedicar-se, o que pode ser demonstrado pelos diversos depoimentos masculinos:

"Eu me preocupo mais com o trabalho"; "Para mim, o trabalho é central"; "O que eu dedico mais tempo é o trabalho, o que acaba forçando teoricamente todo mundo é o trabalho. É o que ocupa a maior parte do meu tempo".

Em contrapartida, o mesmo grupo vai pouco a pouco assumindo um discurso cada vez mais conservador no que se refere à questão análoga proposta: a que atividade a mulher deve se dedicar mais tempo: "No meu caso também o que normalmente seria: a mulher se dedicar mais à família, em casa e tudo"; "Eu também acho que a mulher... eu acho que o ideal seria 
isso, dedicar mais à família". Em tais discursos, torna-se evidente uma concordância com o papel tradicionalmente atribuído à mulher enquanto guardiãmoral da família, tal como descrito por Alice (1989).

Em síntese, de maneira geral, os homens consideram que devem preocupar-se mais com o trabalho, ao passo que afirmam, em quase sua totalidade, que as mulheres deveriam dedicar-se mais à família, para dar mais estrutura à família, em um discurso de nítida naturalização das funçõesfemininas. Para justificar este discurso conservador, os homens recorrem, inclusive, a um critério de credibilidade, justificando suas posições a partir do ponto de vista dos especialistas em educação: "Isso ai é a recomendação de algumas pessoas que trabalham com educação infantil... eles acham que para o desenvolvimento da criança é que ela ficasse até os 5 anos com a mãe em casa."

O utro participante, buscando corroborar a afirmação feita anteriormente, explica a situação da seguinte forma: "É impressionante a diferença destas crianças para outras que às vezes a mãe não tem tempo... é impressionante a diferença... as crianças são mais calmas, mais tranquilas, mais comunicativas...". Para concluir a questão, a discussão se encerra com a seguinte afirmação: "Mãe é mãe. A mulher é preceptora, ela tem que criar os filhos".

No grupo das mulheres, de maneira similar, encontra-se a mesma posição de que os homens devem dedicar-se mais ao trabalho, corroborando uma crença tradicional no acesso naturalizado doshomens no mercado (VENTU RIN I ; RECAM AN , 2004). As mulheres consideram, em quase sua totalidade, que a questão do trabalho para o homem já está determinada, pois conforme diz uma das participantes: "serviço é a honra, ele tem que ir e fazer".No que se refere à atividade principal a que a mulher deve dedicar-se, as opiniões são bastante diferenciadas, demonstrando uma grande dificuldade do grupo em responder a questão. Um dos últimos depoimentos, entretanto, explicita de maneira clara a principal questão proposta por esta pesquisa:

Eu acho que, na verdade, não seria uma atividade pra dedicar mais tempo. Eu acho que a gente tinha que ter 
a capacidade de dimensionar melhor as atividades... Então, acho que a gente tinha, na verdade, não é que ter mais tempo para aquela atividade, mas a gente conseguir, por exemplo: é trabalho? 0 trabalho é de tal hora até tal hora? Então aí acabou o trabalho. Só que, às vezes, a gente não faz isso, não consegue fazer isso. Então acaba que o tempo que você tem para o lazer, que a gente acaba que tem, você não utiliza pro lazer, você utiliza para fazer o trabalho que ficou faltando ou o almoço que você quer adiantar para amanhã.

Este depoimento, corroborado pelas outras participantes do grupo de discussão, revela que a mulher, muitas vezes, vê-se privada de um tempo livre porque, ao chegar em casa, depara-se com mais trabalho: o doméstico. O u seja, o trabalho assalariado e o trabalho doméstico, juntos, ocupam grande parte do tempo feminino. Enquanto os homens se identificam facilmente com o trabalho assalariado, organizando suas vidas em torno dele, para as mulheres parece não existir uma única atividade estruturante, mas múltiplas atividades em que as mulheres se acham envolvidas. Para finalizar, o depoimento de uma participante do grupo das mulheres, que ilustra com muita propriedade esta questão do excesso de tarefas e responsabilidades: "Eu acho que nós nos tornamos escravos do tempo, né? Tudo é muito cronometrado na nossa vida e com isso nós temos nos prejudicado, sim".

\section{Conclusões}

Cabe aqui reiterar algumas questões que se apresentaram como de grande relevância nas observações e análises empreendidas. Claramente, os grupos estudados revelaram a forte presença de discursos socialmente aceitáveis, em que a igualdade entre os gêneros aparece em nível de discurso como um compromisso quase que idealizado para se pensar nas relações entre homens e mulheres. Entretanto, no confronto entre discurso e 
prática, revelam-se inúmeras incoerências. Ao mesmo tempo em que os grupos pesquisados consideram que a educação dos filhos deve ser a mesma, independentemente do sexo, a prática revelada indica que, no domicílio dos participantes, a existência de relações desiguais e assimétricas entre os gêneros é antes a regra do que a exceção.

Para compreender as inúmeras incoerências que perpassaram as discussões dos grupos focais, faz sentido recorrer às tensões presentes na sociedade contemporânea entre a tradição e a modernidade. Apesar de se observar a presença de uma diversidade de arranjos familiares, alguns mais tradicionais, outros mais modernos, a dimensão do conflito nas relações de gênero parece ser o aspecto mais visível e constante. Evidenciou-se, através do discurso dos participantes, a presença de intensas negociações de gênero relativas à distribuição das tarefas domésticas, deixando claro que os ajustes existem, por mais tradicionais que sejam as configurações familiares.

No que diz respeito ao tradicionalismo, ainda presente nas relações familiares, 0 aspecto mais notável foi observado através da recorrente associação entre as mulheres e o cuidado com os filhos. No caso do grupo dos homens, recorreu-se, inclusive, ao discurso de especialistas em educação infantil para a afirmação de que a mulher é uma presença imprescindível e insubstituível, que deve estar efetivamente presente no âmbito doméstico, principalmente quando os filhos ainda são pequenos. No caso das mulheres, o conflito se traduz por exemplo, em um discurso feminista a favor da igualdade de oportunidades entre homens e mulheres no que se refere ao trabalho, concomitante a um discurso favorável a um trabalho nitidamente diferenciado da mulher, com uma carga horária menor do que a do homem para que a mesma possa dedicar-se também, à conservação e cuidado do grupo familiar. Pesquisa recente sobre trabalho e relações de gênero, realizada por Clara Araújo ; Celi Scalon (2004), corrobora essa realidade, ao indicar que a divisão de trabalho entre os membros de um casal, no que diz 
respeito ao cuidado com os filhos, sugere poucas mudanças nos padrões tradicionais.

O utra questão importante observada na pesquisa se refere à maneira diferenciada pela qual homens e mulheres compreendem o que seja "a divisão das tarefas domésticas". Enquanto as mulheres reclamam do pouco envolvimento masculino no trabalho doméstico, os homens possuem um discurso em que se percebem "dividindo efetivamente tais afazeres" com as mulheres. Entretanto, enquanto as mulheres percebem as atividades domésticas como trabalho efetivo, alguns homens as percebem como parte do que chamam de "lazer". Tais diferenças perceptivas merecem uma melhor investigação.

No que se refere à questão da rotinização da vida social, diversas falas apresentaram níveis altos de insatisfação e determinação em alterar-se a ordem vigente. Também fez-se claro que as diferentes inserções sociais dos homens e das mulheres nos universos doméstico e do trabalho, determinam noções muito distintas do papel de cada um nestes espaços e, naturalmente, manejos do tempo e do espaço também muito diferenciados.

De fato, grande parte das mulheres participantes sente-se responsáveis, em igual medida, por tarefas de naturezas muito diversas e que exigem delas a destinação de muito tempo, restando-Ihes, em alguns casos, reduzidos recursos para a experimentação dos espaços/tempo imprescindíveis ao relaxamento e ao desvencilhamento de normas e obrigações. Também averiguou-se, no caso dos homens, que o trabalho aparece nitidamente como atividade estruturante e central em suas vidas, circunscrevendo as tarefas domésticas ao nível do acessório. No caso das mulheres que atuam em casa e no mercado de trabalho, verificou-se que nenhuma das inúmeras tarefas assumidas caracteriza-se como central e organizadora da identidade feminina, nem o trabalho doméstico, nem o assalariado.

Esta duplicidade de responsabilidade e a consequente aceleração de ritmos e cadências vivenciadas por mulheres que procuram manter-se no 
mercado de trabalho sem romper com seus antigos afazeres domésticos, indica o surgimento de um extremo disciplinamento temporal, que traz inúmeras queixas e insatisfações, gerando um elevado nível de conflito para as relações de gênero.

Finalmente a emergência de novos arranjos sexuais de gênero, proposta por Giddens (2002) na modernidade tardia, na qual novas opçõese diversidade de ações alterariam reflexivamente as rotinas, vislumbra alternativas às desigualdad es encontradase, a partir daí, o surgimento de possibilidades para uma possível desaceleração das mulheres, que vivenciariam tempos e espaços propícios a uma organização mais seletiva e livre do seu tempo. Essas possibilidades, entretanto, precisam ser repensadas a partir da subversão de dimensões essencializantes acerca de homens e mulheres, pois estas dimensões morais revelam-se extremamente resistentes à mudança, contribuindo para o surgimento de inúmeras defasagens entre 0 discurso e a prática. Romper com a associação do feminino com o doméstico não é tarefa fácil, pois implica em se desmontar pressupostos morais, crenças e valores estabelecidos sobre as diferenças entre homens e mulheres. Implica em se questionar representações de gênero tradicionais que contribuem para criar um meio discursivo em que diferenças socialmente construídas são vistas como inevitáveis e naturais.

\section{Work, temporality and gender relations: an analysis of the relationship between housework and paid work}

\section{Abstract}

This article examines the "work and gender" question through the relationship between housework and paid work, considering that one of the key factors to explain the unequal insertion of men and women in the labor market is related to the issue of reconciliation between work and family life. Despite being a preliminary 
study, the author intends to develop a research hypothesis to be examined in further studies on the nature of the central role that the work usually plays in the lives of women. Thus, the paper aims to contribute in some way to the advancement of researches on the complex relationships between career and family life.

Keywords: Housework. Paid work. Gender relations. Career and family life. Temporality.

\section{Referências}

AGUIAR, Neuma. Gênero e Ciências Humanas: desafio às ciências desde a perspectiva das mulheres. Rio de Janeiro: Editora Rosa dos Tempos, 1997. 191p. (Coleção Gênero).

ALICE, Inês de Oliveira. Abelhinhas numa diligente colméia: domesticidade e imaginário feminino na década de cinquenta. In: COSTA, Albertina de O liveira, BRUSCHINI, Cristina (O rg.). Rebeldia e submissão: estudos sobre a condição feminina. São Paulo: Vértice, Editora Revista dos Tribunais: Fundação Carlos Chagas, 1989.

ARAÚJO, Clara ; SCALO N, Ceci. Gênero, família e trabalho no Brasil. Rio de Janeiro: Editora FGV, 2005. 304p.

BARBIERI, Terezita de. Sobre la categoria gênero: una introduccion teoricometodologica. ISIS, abr. 1992. p. 111-128.

BELLE, F. Executivas: quais as diferenças na diferença. In: CHANLAT, J.F. 0 indivíduo na organização: dimensões esquecidas. V2. São Paulo: Atlas, 1994, 285p. p. 196-231.

BRU SCHINI, Cristina. Fazendo as perguntas certas: como tornar visível a contribuição econômica das mulheres para a sociedade? Águas de Lindóia: trabalho apresentado no II Congresso Latino-americano de Sociologia do Trabalho, 1996.

. Gênero e trabalho no Brasil: novas conquistas ou persistência da discriminação?. In: ROCHA, M. (org.). Trabalho e Gênero: mudanças, permanências e desafios. Campinas: CEDEPLAR, 2000, 384p. p. 13-58.

CAPPELIN, Paola. Conciliar vida familiar e trabalho em tempo de crise do emprego. Trabalho apresentado no XII Congresso Brasileiro de Sociologia, Belo Horizonte, 2005.

CHODOROW, Nancy. Estrutura familiar e personalidade feminina. In: A mulher, a cultura e a sociedade. Rio de Janeiro: Paz e Terra, 1979. 
D ED ECCA, Cláudio Salvadori. Tempo, trabalho e gênero. Campinas: IE/ U nicamp, 2004.

FRIED M AN N, Georges; NAVILLE, Pierre. Tratado de sociologia do trabalho. São Paulo: Ed. Cultrix, 1973.

GIDDENS, Anthony. Modernidade e identidade. Rio de Janeiro: Jorge Zahar Editor, 2002. 233p.

GOLDENBERG, Mirian. Ser homem, ser mulher: dentro e fora do casamento. Rio de Janeiro: Revan, 1991. 126p.

HAGERSTRAND, T. "A note on the quality of the life-times". In CARLSTEIN, T.; PARKERS, D,; THRIFT, N. Time space and spacing time. Londres: Edward Arnold Publishers, 1978, $320 \mathrm{p}$.

HARAWAY, Donna. Simians, Cyborgs and Women: The Reinvention of $\mathrm{N}$ ature. New York: Routledge, 1995.

HEILBO RN, Maria L. Gênero e especificidade da condição feminina. Rio de Janeiro, CIEC/UFRJ., 1998.

HIRATA, H elena. Nova divisão sexual do trabalho: um olhar voltado para a empresa e a sociedade. São Paulo: Editora Boitempo, 2002, 335p.

M ELO, Hildete Pereira de, CO NSIDERA, Claudio M onteiro, SABBATO, Alberto Di. Os afazeres domésticos contam. Disponível em: http://www.uff.br/econ.htm. Acesso em: 03 março 2006.

M O RGAN, David L. Focus Group As Q ualitative Research. Thousand oaks, CA: 1997.

MO SCO VICl, Serge. Representações sociais: investigações em psicologia social. Rio de Janeiro: Petrópolis, 2005.

PATEM AN, Carole. 0 contrato sexual. Rio de Janeiro: Editora Paz e Terra, 1993. PU PPIN, Andréa Brandão. Do lugar das mulheres e das mulheres fora de lugar: um estudo das relações de gênero na empresa. Rio de Janeiro: Editora da Universidade Federal Fluminense, 2001. 221p.

RAGO, Margareth. Ser mulher no século XXI ou Carta de Alforria. In: A mulher brasileira nos espaços público e privado. São Paulo: Editora Fundação Perseu Abramo, 2004.

ROSISKA, Darcy de O liveira. Reengenharia do tempo. Rio de Janeiro: Rocco, 2003. 148p.

SO RJ, Bila. Trabalho remunerado e não-remunerado. In: A mulher brasileira nos espaços público e privado. São Paulo: Editora Fundação Perseu Abramo, 2004. 
SCHUTZ, Alfred. Fenomenologia e relações sociais. Rio de Janeiro: Zahar, 1970. SCOTT, Joan Wallach. Gênero: uma categoria útil de análise histórica. Revista Educação e Realidade, Porto Alegre, v. 15, n. 2, p. 11-38, jul./dez. 1991.

TILLY, Louise. Gênero, história das mulheres e história social. Cadernos Pagu, Campinas, n. 3, p. 29-62, 1994.

VENTU RINI, Gustavo; RECAM ÁN, M arisol; O LIVEIRA, Sueli de. As mulheres brasileiras no início do século XXI. In: A mulher brasileira nos espaços público e privado. São Paulo: Editora Fundação Perseu Abramo, 2004.

Recebido: $05 / 12 / 06$ Aceite final: 02/02/07 